\title{
A comparative look at structural variation among RC-LH1 'Core' complexes present in anoxygenic phototrophic bacteria
}

\author{
Alastair T. Gardiner ${ }^{1,2}$ (D) Tu C. Nguyen-Phan ${ }^{1}$ (D) Richard J. Cogdell $^{1}$ D
}

Received: 26 March 2020 / Accepted: 10 May 2020 / Published online: 19 May 2020

(c) The Author(s) 2020

\begin{abstract}
All purple photosynthetic bacteria contain RC-LH1 'Core' complexes. The structure of this complex from Rhodobacter sphaeroides, Rhodopseudomonas palustris and Thermochromatium tepidum has been solved using X-ray crystallography. Recently, the application of single particle cryo-EM has revolutionised structural biology and the structure of the RC-LH1 'Core' complex from Blastochloris viridis has been solved using this technique, as well as the complex from the non-purple Chloroflexi species, Roseiflexus castenholzii. It is apparent that these structures are variations on a theme, although with a greater degree of structural diversity within them than previously thought. Furthermore, it has recently been discovered that the only phototrophic representative from the phylum Gemmatimonadetes, Gemmatimonas phototrophica, also contains a RC-LH1 'Core' complex. At present only a low-resolution EM-projection map exists but this shows that the Gemmatimonas phototrophica complex contains a double LH1 ring. This short review compares these different structures and looks at the functional significance of these variations from two main standpoints: energy transfer and quinone exchange.
\end{abstract}

Keywords Purple photosynthetic bacteria $\cdot$ Light harvesting $\cdot$ Structures $\cdot$ Reaction centres $\cdot$ Anoxygenic phototrophs $\cdot$ RCLH1

\begin{tabular}{ll}
\multicolumn{2}{l}{ Abbreviations } \\
AAP & Aerobic anoxygenic phototroph \\
AFM & Atomic force microscopy; \\
Bchl & Bacteriochlorophyll \\
Blc & Blastochloris \\
Bphe & Bacteriopheophytin \\
Gem & Gemmatimonas \\
ICM & Intra-cytoplasmic membrane \\
LH & Light harvesting \\
MQ & Menaquinone \\
NIR & Near infrared \\
PSU & Photosynthetic unit \\
Phs & Phaeospirillum \\
RC & Reaction centre \\
Rbl & Rhodoblastus
\end{tabular}

Alastair T. Gardiner gardiner@alga.cz

1 Institute of Molecular, Cellular and Systems Biology, College of Medical, Veterinary and Life Sciences, University of Glasgow, Glasgow G12 8QQ, UK

2 Laboratory of Anoxygenic Phototrophs, Centre Algatech, Institute of Microbiology of the Czech Academy of Sciences, Novohradska 237, 37901 Třeboň, Czech Republic

\section{Rof Roseiflexus \\ Rsp Rhodospirillum \\ Rps Rhodopseudomonas \\ Tch Thermochromatium \\ UQ Ubiquinone}

\section{Introduction}

The intra-cytoplasmic membranes (ICM) of anaerobic phototrophic bacteria contain all the pigment-protein complexes necessary for photosynthetic growth. In the ICM, the lightharvesting $(\mathrm{LH})$ antenna that is intimately associated in a complex with a type- 2 reaction centre (RC) is known as the RC-LH1 'Core' complex and forms the 'heart' of the photosynthetic unit (PSU). In many species, the PSU consists of both a RC-LH1 'Core' complex and peripheral antenna complexes termed LH2. However, there are species of anoxygenic phototrophic bacteria, e.g. Rhodospirillum (Rsp.) rubrum and Blastochloris (Blc.) viridis that contain PSUs with only RC-LH1 'Core' complexes (i.e. no LH2) and are perfectly able to sustain photosynthetic growth (Aagaard and Sistrom 1972; Eimhjellen et al. 1963). 
To help understand fully the function of the ICM, it is necessary to have high-resolution structures of the constituent protein complexes. The development and availability of a broad range of mild, non-ionic and zwitterionic detergents has had a dramatic effect upon the study of membrane biology and the proteins present in photosynthetic membranes are no exception. The go-to approach, at least until recently, was to obtain high-resolution structural information by growing protein crystals of the desired complex for X-ray crystallography (these complexes are generally not yet suitable for NMR analyses (Liang and Tamm 2016; McDermott 2009).The ability to easily and reproducibly purify stable, intact complexes to homogeneity has led to structural determination of the RC and LH2. However, for many years equivalent structural data about RC-LH1 'Core' complexes were lacking. These complexes have some intrinsic characteristics that mean they are not ideally suited for growing the large, highly ordered crystals necessary for X-ray studies. Compared with most other membrane proteins, there are almost no extra-membrane hydrophilic domains/regions and, the fixed Cytochrome $c$ subunit excepted (if present), all the RC-LH1 'Core' complex functionality takes place within the hydrophobic, membrane spanning region. After solubilisation, a large proportion of the complex is, by necessity, shrouded within the detergent micelle and this hinders the formation of strong, stable, protein-protein crystal contacts. The fixed Cytochrome $\mathrm{c}$ and the cytoplasmic-side $\mathrm{H}$-subunit domain may be able to form good contacts, as they are generally out of the detergent micelle. Such contacts, however, can lead to the fixed Cytochrome $\mathrm{c}$ making contact with the H-subunit of a neighbouring molecule in the lattice in a repeating head-to-toe arrangement, resulting in a crystal that is a flat, two-dimensional plate and produces only anisotropic diffraction. Three-dimensional crystals of antenna complexes also have a relatively high solvent content, $70 \%$ (Roszak et al. 2003), resulting in the requirement for large crystals that contain a sufficient number of molecules to enable diffracted X-rays to be detected. RC-LH1 'Core' complex crystals that are suitable for X-ray crystallography have, therefore, to overcome the contradictory requirements for large crystals but without the ability to form strong, stable crystal contacts. As the crystal grows, the inherent, long-range disorder in the lattice increases and so it diffracts poorly. Nevertheless, persistent and methodical optimisation of crystals has resulted in RC-LH1 'Core' complex structures using X-ray crystallography from Rhodopseudomonas (Rps.) palustris at $4.8 \AA$, pdb 1PYH (Roszak et al. 2003) and Tch. tepidum at $3.0 \AA$, pdb 3WMM (Niwa et al. 2014), subsequently improved to $1.9 \AA$, pdb 5Y5S (Yu et al. 2018).

Over the past few years, structural biology has been revolutionised by the rapid and on-going advancement in cryoEM technology. Cryo-EM has made possible near atomic level structure determination from single particles quickly, without the need for crystallisation, large amounts of protein or even for the protein to be $100 \%$ homogeneous. These advances were recognised by the award of the 2017 Nobel Prize in Chemistry to Jacques Dubochet, Joachim Frank, and Richard Henderson (Nogales 2018).

It is worthwhile to make a brief comparison between the determination of protein structures by X-Ray crystallography and cryo-EM. In principle, given equivalent resolution the two techniques should produce equally reliable structures. However, it is worth examining this a bit more critically. When X-Ray crystallography is used to solve a protein structure, then it is assumed that all the protein molecules in the crystal are identical. In a general sense this is true (otherwise there would not be a crystal), but the technique is not able to differentiate between individual protein molecules in the lattice. A difference electron density map is generated that undergoes an iterative process of refinement using the co-ordinates and structure factors to generate the final, robust structure. Solving a protein structure with cryoEM involves a more linear workflow but initially makes the same assumption that all the molecules selected from the EM grid are identical. One can select, sort and overlay with the software different populations of individual particles to produce a coulomb potential map of the molecule. Inherent heterogeneity within the particles means that it is more difficult to align all the regions molecules equally and results in a distribution of resolution across the map. It is important to bear in mind, therefore, that the meaning of 'resolution' is slightly different for a cryo-EM structure compared with an $\mathrm{X}$-ray structure. The ability to computationally select particles means that it is possible to look for changes in protein structure between populations. In this way, cryo-EM can detect conformational forms of proteins that would be hard, if not impossible, to visualise using X-Ray crystallography.

Within a very short timescale, research into photosynthetic complexes has benefitted greatly from the application of cryo-EM: for complexes that previously produced only poorly diffracting crystals (or were not able to be crystallised at all) and to multi-complex super assemblies that would be extremely difficult to crystallise intact, for example the phycobilisome, with cryo-EM structures already available from the red alga Griffithsia pacifica at $3.5 \AA$, pdb 5Y6P 
(Zhang et al. 2017) and Porphyridium purpureum at $2.82 \AA$, pdb 6KGX (Ma et al. 2020). The application of cryo-EM has now produced high-resolution structures for the RC-LH1 'Core' complex from Blc. viridis to $2.9 \AA$ A, pdb 6ET5 (Qian et al. 2018) and the RC-LH Roseiflexus (Rof.) castenholzii to $4.1 \AA$, pdb 5 YQ7 (Xin et al. 2018).

With the availability of these RC-LH1 'Core' complexes, obtained using both X-ray crystallography and cryo-EM, it has become clear that there is a much greater degree of structural variation within them than previously considered (Cogdell and Roszak 2014). In this concise mini-review, the structures are presented in a historical context and compared by highlighting the respective similarities and differences. It is neither our intention nor wish to reproduce the fine structural details (residues, distances, H-bonds, etc.) that are characteristic of each complex. Interested readers should refer to the corresponding publications, where these features are covered fully. Table 1 provides an overview of the main features from the different structures, which are then described in more detail below.

In general, all RC-LH1 'Core' complexes must fulfil two basic functions (Barz et al. 1995a, b; Cogdell et al. 2004; McGlynn et al. 1994; Sundström and van Grondelle 1995). Firstly, they provide an excitation energy transfer conduit that links light absorption by the antenna system to charge separation in the reaction centre ( $\mathrm{RC})$. Once excited, the $\mathrm{RC}$ catalyses the primary, transmembrane electron-transfer reactions that result in a quinone molecule being reduced to a quinol. Secondly, the quinol must then be able to pass through the LH1 ring and equilibrate with the bulk quinone pool in the membrane to maintain the cyclic electron transport pathway via the cytochrome $b / c_{1}$ complex. This ultimately creates a transmembrane electrochemical proton gradient and drives the synthesis of ATP (Hu et al. 1998; Moser et al. 2003). Studies of RC-LH1 'Core' complexes should always consider these two basic functions, namely energy transfer and quinone/quinol exchange, how they are achieved and the advantages and disadvantages that any particular structural variant confers.

\section{Discussion}

In 1995, an $8.5 \AA$ electron microscopy projection structure of the Rsp. rubrum LH1 complex was determined (Karrasch et al. 1995). The 2D crystals in this study were produced from reconstituted, detergent-solubilised $\alpha \beta$-subunits and the projection map revealed a closed, circular 16-mer ring formed from these repeating dimers. This finding was somewhat controversial at the time, as it was thought that a

Table 1 A comparison of the RC-LH1 'Core' complexes from the anoxygenic phototrophs mentioned in the text

\begin{tabular}{|c|c|c|c|c|c|c|c|c|c|}
\hline Species & Resolution & Method & LH1 ring shape & $\begin{array}{l}\text { LH1 apopro- } \\
\text { teins }\end{array}$ & LH1 pigments & RC pigments & RC subunits & $\begin{array}{l}\text { Quinone/quinol } \\
\text { exchange }\end{array}$ & Other subunits \\
\hline Rps. palustris & $4.8 \AA$ & X-ray & $\begin{array}{l}\text { Elliptical ring } \\
\text { with gap }\end{array}$ & $15 \alpha \beta$ & 30 Bchl a (B880) & Not resolved & $\mathrm{L}, \mathrm{M}, \mathrm{H}$ & $\begin{array}{l}\text { Protein W-induced } \\
\text { channel }\end{array}$ & Protein W \\
\hline Rba. sphaeroides & $8 \AA$ & $\begin{array}{c}\text { X-ray/NMR/ } \\
\text { EM/MS }\end{array}$ & $\begin{array}{l}\text { LH1 ribbon } \\
\text { enclosing two } \\
\text { RC }\end{array}$ & $28 \alpha \beta$ & $\begin{array}{l}56 \text { Bchl a (B875): } \\
56 \text { sphaeroidene }\end{array}$ & $\begin{array}{l}2 \times(4 \text { Bchl } a: 4 \\
\text { Bphela }) \\
2 \times \text { sphaeroidene } \\
\mathrm{UQ}_{10}, \mathrm{UQ}_{10}\end{array}$ & $\mathrm{~L}, \mathrm{M}, \mathrm{H}$ & $\begin{array}{l}\text { PufX-induced } \\
\text { channel }\end{array}$ & Protein PufX \\
\hline Blc. viridis & $2.9 \AA$ & Cryo-EM & $\begin{array}{c}\text { Elliptical ring } \\
\text { with a pore }\end{array}$ & $\begin{array}{c}16 \alpha \beta \gamma \text { trimers, } \\
1 \alpha \beta \text { dimer }\end{array}$ & $\begin{array}{l}34 \mathrm{Bchl} b(\mathrm{~B} 1015) \text { : } \\
17 \text { 1,2-dihydro- } \\
\text { neurosporene and } \\
\text { dihydro-lycopene }\end{array}$ & $\begin{array}{l}4 \mathrm{Bchl} b: 2 \\
\text { Bphe } b \text { : } \\
\text { 1,2-dihydro- } \\
\text { neurosporene } \\
\mathrm{MQ}_{9}, \mathrm{UQ}_{9}\end{array}$ & $\mathrm{~L}, \mathrm{M}, \mathrm{H}, \mathrm{C}$ & $\begin{array}{l}\text { LH1 ring pore due to } \\
\text { the 'missing' } 17^{\text {th }} \\
\gamma \text {-polypeptide }\end{array}$ & None \\
\hline Tch. tepidum & $1.9 \AA$ & X-ray & $\begin{array}{l}\text { Completely } \\
\text { closed ellipti- } \\
\text { cal ring }\end{array}$ & $16 \alpha \beta$ & $\begin{array}{l}32 \text { Bchl a } \\
16 \text { spirilloxanthin }\end{array}$ & $\begin{array}{l}4 \text { Bchl a: } 2 \\
\text { Bphe } a \text { : } \\
\text { Spirilloxanthin } \\
\mathrm{MQ}_{8}, \mathrm{UQ}_{8}\end{array}$ & $\mathrm{~L}, \mathrm{M}, \mathrm{H}, \mathrm{C}$ & $\begin{array}{l}\text { No gap/pore, } \\
\text { exchange occurs } \\
\text { through the LH1 } \\
\text { alpha helices }\end{array}$ & None \\
\hline Rof. castenholzii & $4.1 \AA$ & Cryo-EM & Elliptical ring & $15 \alpha \beta$ & $\begin{array}{l}45 \mathrm{Bchl} \text { a } \\
(30 \mathrm{~B} 880 \\
15 \mathrm{~B} 800) \\
14 \text { keto- } \alpha \text {-carotene }\end{array}$ & $\begin{array}{l}3 \text { Bchl a: } 3 \\
\text { Bphe a } \\
\text { No resolved } \\
\text { carotenoid } \\
\mathrm{MQ}_{11}, \mathrm{MQ}_{11}\end{array}$ & $\mathrm{~L}, \mathrm{M}, \mathrm{C}$ & $\begin{array}{l}\text { Channel composed of } \\
\text { a fixed Cyt } c \text { helix, } \\
\text { the } 15^{\text {th }} \mathrm{LH} \alpha \beta \text { and } \\
\text { the flexible trans- } \\
\text { membrane helix of } \\
\text { the subunit } X\end{array}$ & fSubunit X \\
\hline
\end{tabular}

The table is compiled from the following: Rps. palustris (Roszak et al. 2003), Rba. sphaeroides (Qian et al. 2013), Blc. viridis (Qian et al. 2018), Tch. tepidum (Yu et al. 2018), Rof. castenholzii (Xin et al. 2018) 
closed ring would render quinone/quinol exchange through the palisade of $\alpha$-helices impossible. Albeit many years later, the authors were vindicated with the publication of the Tch. tepidum RC-LH1 'Core' (Niwa et al. 2014), which also has a closed ring. Subsequently, Jamieson et al. (2002) also published an $8.5 \AA$ projection structure of RC-LH1 'Core' complex from Rsp. Rubrum; however, the 2D crystals in this study came from intact, purified complexes rather than reconstituted subunits. Maps were calculated from two different crystal forms, one of which showed a circular LH1 ring and the other an elliptical LH1 ring. This was the first direct, experimental evidence that LH1 rings could be non-circular. Interestingly, later atomic force microscopy (AFM) studies on ICM from Blc. viridis revealed that when the LH1 ring is enclosed by a RC, the ring shape is then elliptical. When the RC was nano-dissected out with the AFM tip to leave only the LH1 ring, then it relaxed into a more circular structure (Scheuring et al. 2003). This is strong, direct experimental evidence that the shape of the LH1 ring is modulated by interactions with the RC. AFM has proven to be a very useful technique to show the overall size and shape of the 'RC-LH1 'Core' complexes in intact ICM and how they may be organised relative to each other and to LH2 complexes. As such, AFM is an important tool to aid understanding of these high-resolution structures in the context of the native PSU. However, due to its relatively low resolution compared with either X-Ray crystallography or cryo-EM, AFM should be used rather conservatively when trying to determine subunit stoichiometry or gaps within these antenna 'rings'.

Long before there were 3D structures of RC-LH1 'Core' complexes, the primary structure of many LH1 apoproteins was determined by both protein and gene sequencing (Zuber and Cogdell 1995). Alignment of these sequences revealed that they were all highly homologous (Brunisholz and Zuber 1988), relatively short polypeptides of typically 50-60 amino acids (5-7 kDa) and predicted to have hydrophilic ends separated by a single transmembrane spanning $\alpha$-helix containing a single conserved His residue. This is nicely illustrated in Qian et al. (2018) (Extended data Fig. 9), as these authors published an alignment of some representative LH $1 \alpha$ - and $\beta$-polypeptide sequences. CLUSTAL O v.1.2.4 analyses of these sequences reveals that the $\alpha$ - and $\beta$-sequences matched against each other have a residue identity of $39 \%$ and $43 \%$, respectively. If strongly conserved and/ or weakly conserved changes are also taken into account, then that value increases even more. It was suggested that this His residue is co-ordinated to the central $\mathrm{Mg}$ atom in the middle of the bacteriochlorin ring of bacteriochlorophyll (Bchl) (Zuber 1987). These main conclusions, all drawn from a rather simple comparison of LH1 apoprotein primary structures, are clearly borne out in all the following structures. The LH1 'ring' that is formed around the RC is made from a repeating oligomer of a basic heterodimeric structure composed of an $\alpha$ - and $\beta$-apoprotein pair (Qian et al. 2013; Roszak et al. 2003; Yu et al. 2018), in an analogous manner to LH2 complexes (Gabrielsen et al. 2009), with the light absorbing pigments, $\mathrm{Bchl}$ and carotenoids, bound non-covalently. Figure 1 illustrates two of these $\alpha \beta$-dimers together (i.e. as they are in the ring), for the species presented in this review and for which there are high-resolution structures available, along with an equivalent view of a 'double $\alpha \beta$-dimer' from the LH2 complex of Rhodoblastus (Rbl.) acidophilus (formerly Rps. acidophila) strain 10050 for comparison, pdb 1NKZ. The importance of the conserved His residue (coloured pink in Fig. 1) that co-ordinates to the central $\mathrm{Mg}$ atom in the middle of the bacteriochlorin ring is clearly evident. The composition of the $\alpha \beta$-dimer subunit that makes up LH2 complexes is rather standardised, Fig. 1a, consisting of the $\alpha \beta$-dimer, three Bchl $a$ and one carotenoid. Depending on the species, these $\alpha \beta$-dimer units can oligomerise to form LH2 complexes with different ring sizes, for example, Rbl. acidophilus (McDermott et al. 1995) and Rps. palustris (Southall et al. 2018) make a nonameric complex, Phaeospirillum (Phs.) molischianum (Koepke et al. 1996) makes an octameric complex and Allochromatium vinosum is thought to make a dodecameric complex (Kereïche et al. 2008). The ring size can change but the composition of the ring remains very similar. However, it is now known that the composition of the subunits that oligomerise to form the LH1 ring in RC-LH1 'Core' complexes is not constant; Blc. viridis contains an additional $\gamma$-polypeptide (Fig. 1b), Tch. tepidum contains a bound $\mathrm{Ca}^{2+}$ ion (Fig. 1c) and Rof. castenholzii contains an additional Bchl (Fig. 1d). Clearly, LH1 (and LH2) rings are capable of forming many different sizes and it is interesting to ask where and how the information for the oligomeric size is encoded? Perhaps, as it has been suggested (Pugh et al. 1998), the precise way in which the LH1 ring assembles around the RC controls the resultant ring size. Clearly further work is required to answer this fascinating question.

The pairs of Bchl are strongly exciton coupled and interact around the LH1 ring to give rise to the well-known single strong $\mathrm{Q}_{\mathrm{y}}$ absorption band in the near infrared (NIR), illustrated in Fig. 2. It is apparent that some of the absorption spectra are mostly rather similar, differing mainly in the exact position of the peak of the $\mathrm{Bchl} a \mathrm{Q}_{\mathrm{y}}$ band. Monomeric Bchl $a$ in organic solvents, such as 7:2(v/v) acetone:methanol, has a $\mathrm{Q}_{\mathrm{y}}$ band that absorbs at $772 \mathrm{~nm}$ (Clayton 1966). The precise reason why these complexes have a different $\mathrm{Q}_{\mathrm{y}}$ absorption band red shift has been a long-standing open question. The factors that can, in principle, produce red shifts of the $\mathrm{Bchl} \mathrm{Q}_{\mathrm{y}}$ absorption band have been considered in detail elsewhere (Cogdell et al. 2002; Robert et al. 2003). In general, the overall molecular environment of any individual $\mathrm{Bchl}$ in its binding pocket 
a
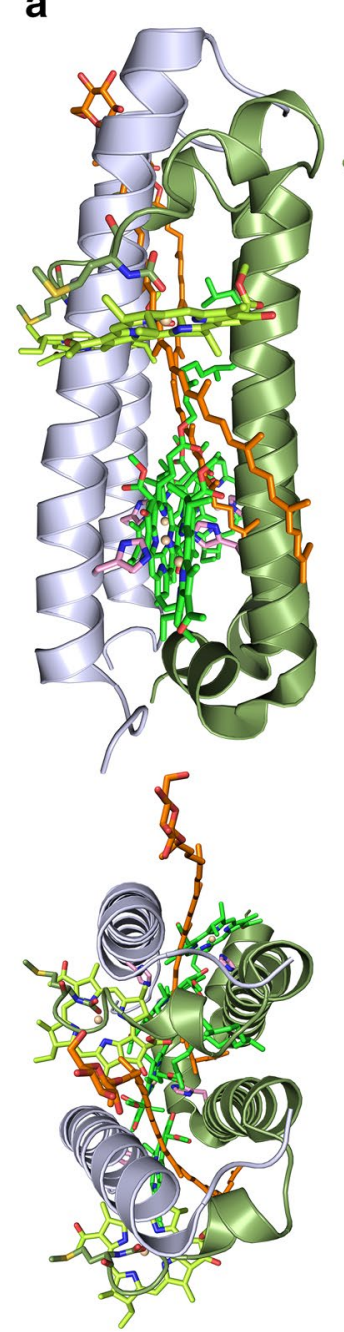

b
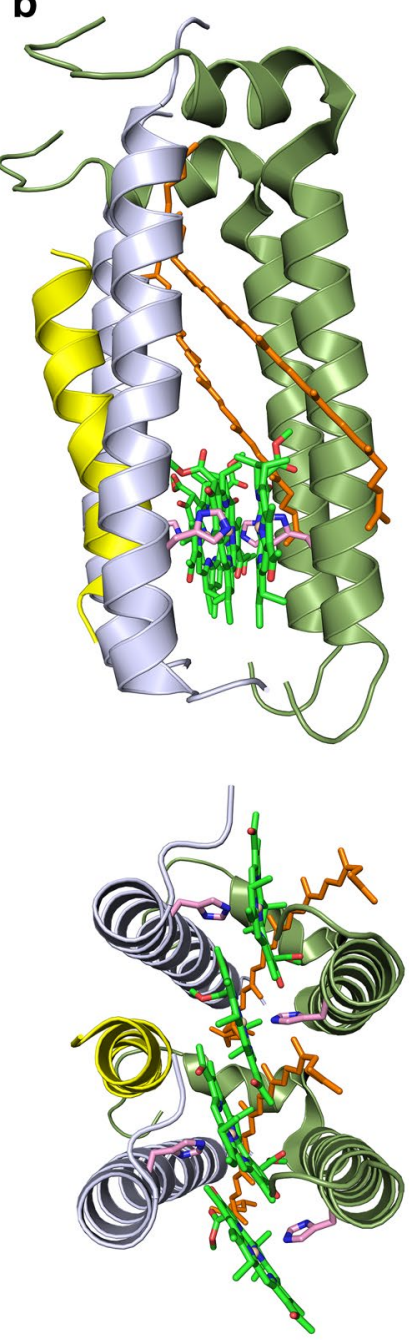

d
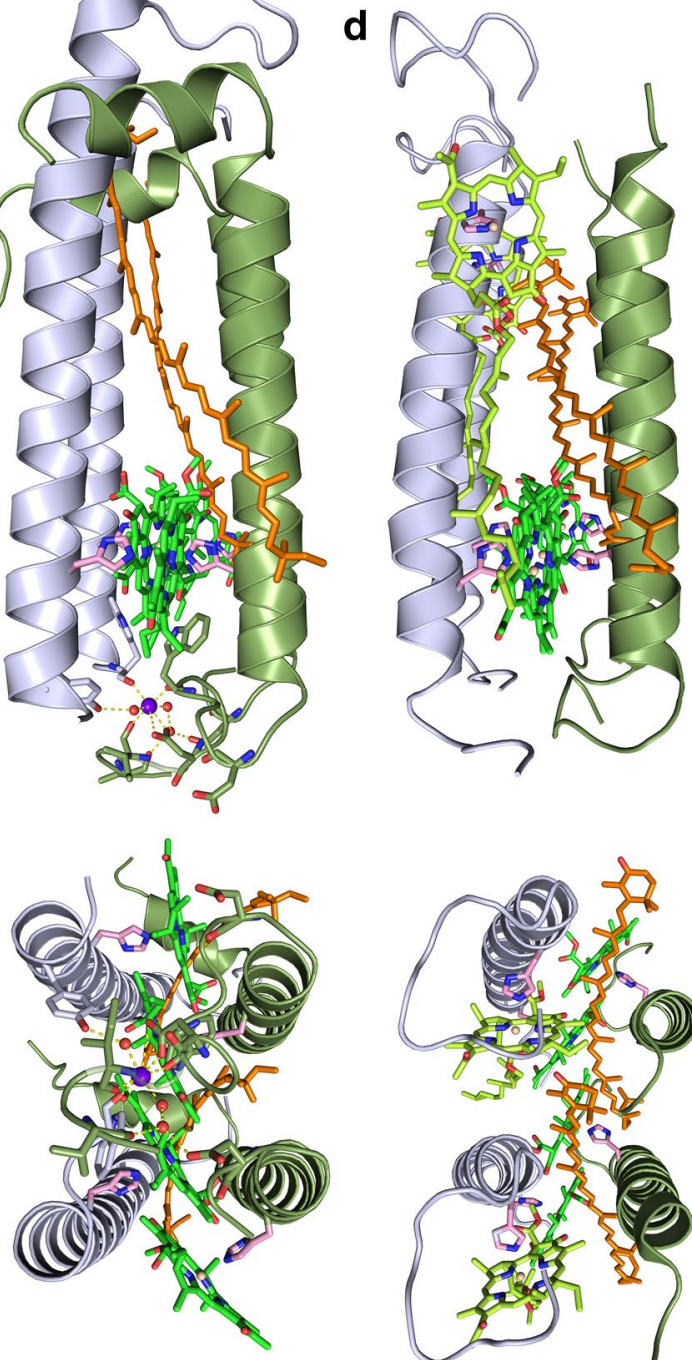

C
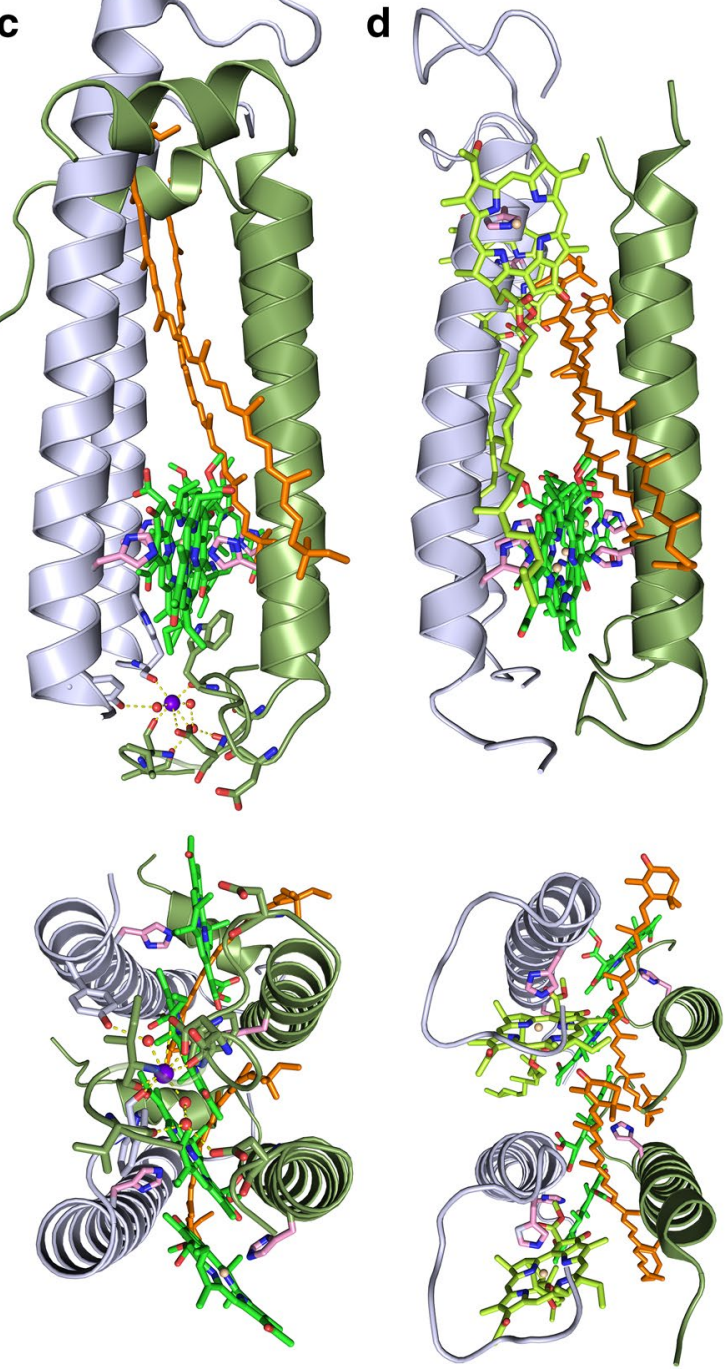

Fig. 1 Two $\alpha \beta$-dimers in the ring of the light-harvesting complexes. Each view is slightly adjusted for maximal visibility. The Bchl tails and last few residues from some of the polypeptide chains have been omitted for clarity. The top row is in the plane of the membrane and bottom row is normal to the membrane. Common colours; $\alpha$-polypeptides-purple blue, $\beta$-polypeptides-olive, ring Bchlgreen, monomeric Bchl-lemon, carotenoids-orange, coordinating His residues-pink. a For comparison, a double $\alpha \beta$-dimer from the LH2 complex from Rbl. acidophilus. The monomeric Bchl is liganded to the $\mathrm{C}$-terminal of the $\alpha$-chain through a carboxy modi-

sets that Bchl's site energy. In addition, exciton coupling between the strongly interacting Bchl molecules in the LH1 ring causes a further red shift. The extent of this shift then depends on the precise strength of this exciton coupling as well as other factors such as charge-transfer states (Nottoli et al. 2018). It can be seen from Fig. 2 that Rof. castenholzii (Fig. 2a brown) and Gemmatimonas (Gem.) phototrophica (Fig. 1b pink) have RC-LH1 'Core' complex spectra that are

fied $\alpha$-Met. The lower view is from the periplasmic side. b Blc. viridis with the additional $\gamma$-helix in yellow on the outside of the LH1 ring and between two $\beta$-helices. The lower view is from the cytoplasmic side. c Tch. tepidum with the co-ordinated $\mathrm{Ca}^{2+}$ on the cytoplasmic side shown in magenta and the water molecules as red spheres. This network of bonds requires residues from both $\alpha \beta$-dimers. The lower view is from the cytoplasmic side and part of the C-terminal $\alpha$-polypeptide chain has been made partially transparent for clarity. $\mathbf{d}$ Rof. castenholzii with the monomeric Bchl liganded to a His residue on the $\alpha$-polypeptide. The lower view is from the cytoplasmic side markedly different as they have two strong $\mathrm{Bchl} \mathrm{Q}_{\mathrm{y}}$ absorption peaks in the NIR rather than one. The Rof. castenholzii complex has a minor band at $800 \mathrm{~nm}$ and a major band at $879 \mathrm{~nm}$ (Xin et al. 2012; Yamada et al. 2005), whereas the Gem. phototrophica RC-LH1 'Core' has a major band at $816 \mathrm{~nm}$ and a minor band at $868 \mathrm{~nm}$ (Dachev et al. 2017). A typical LH2 complex, such as the one from Rbl. acidophilus strain 10050 (Fig. 2c orange dash), also has two NIR Bchl 


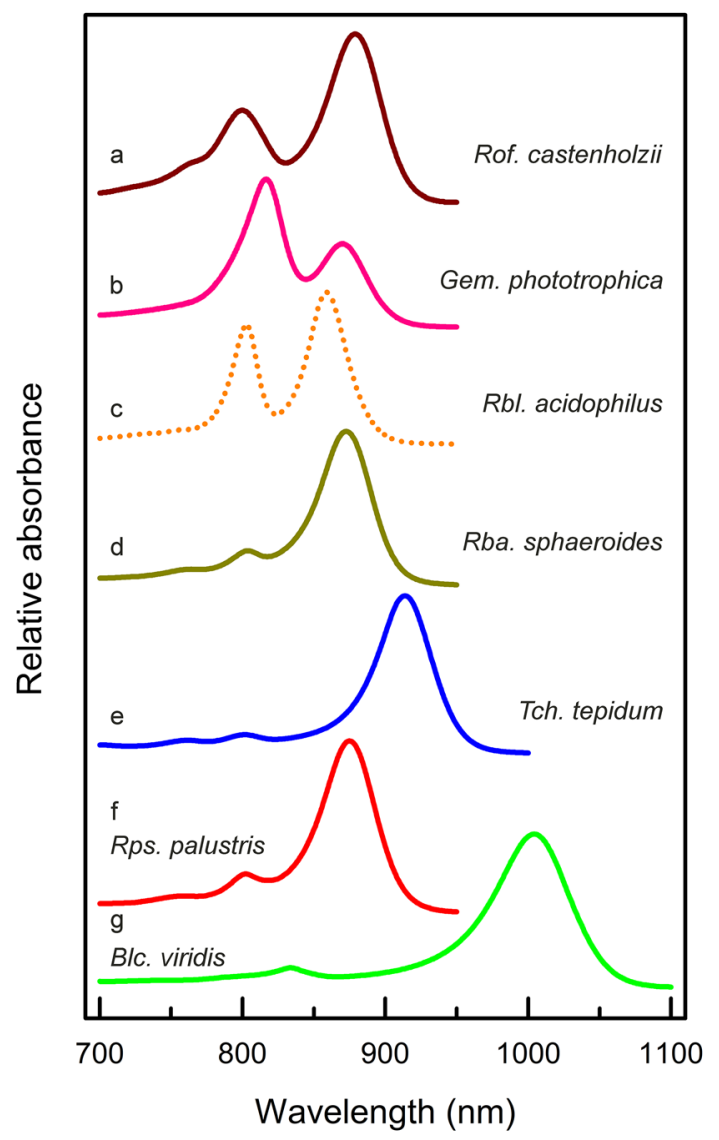

Fig. 2 NIR absorption spectra of the RC-LH1 complexes mentioned in the text. The colour assignments are as follows along with the respective complex absorption band maxima (nm); a Rof. castenholzii, brown (800, 879), b Gem. phototrophica, pink (816, 868), c Rbl. acidophilus LH2, orange (804, 858), d Rba. sphaeroides, olive (873), e Tch. tepidum, blue (914), Rps. palustris, red (875), d Blc. viridis, green (1004)

$a \mathrm{Q}_{\mathrm{y}}$ absorption bands, in this case at $804 \mathrm{~nm}$ and $858 \mathrm{~nm}$ (Gardiner et al. 1993) and is known as a B800-850 complex. There are also other variants of LH2 that have different absorption spectra, for example, Rbl. acidophilus strain 7050 makes a 'standard' B800-850 complex at high-light but a B800-820 complex (formerly known as LH3) under lowlight growth conditions. Rps palustris makes a heterologous LH2 complex, in which the B800-850 complex produced under low-light (previously called LH4) has a B850 band absorption that is substantially reduced compared with the high-light adapted 'standard' B800-850. In all these LH2 complexes, the population of Bchl $a$ molecules that absorb at $\sim 800 \mathrm{~nm}$ is less strongly excitonically coupled than the population absorbing at ( $\sim 820$ to $) \sim 850 \mathrm{~nm}$, and so the red shift is not as pronounced. It is apparent, therefore, that the RC-LH1 'Core' complexes from Rof. castenholzii (Collins et al. 2010) and Gem. phototrophica (Dachev et al. 2017) are different to those previously characterised from purple bacteria. They are RC-LH1 'Core' complexes but also have features of LH2 as they contain two populations of $\mathrm{Bchl} a$ molecules, one strongly excitonically coupled and the other weakly coupled. The following sections that deal with the Rof. castenholzii and Gem. phototrophica complexes will reveal the completely different structural solutions adopted by these species, which enable the polypeptides to act as a scaffold for these two (one strongly and one weakly coupled) Bchl $a$ populations. For the Rba. sphaeroides (Fig. 2d olive), Tch. tepidum (Fig. 2e blue) and Rps. palustris (Fig. 2f red) spectra, the small peak just to the blue of the main LH1 NIR Bchl $a \mathrm{Q}_{\mathrm{y}}$ absorption band $(\sim 800 \mathrm{~nm})$ originates from the RC. The RC peak from Blc. viridis is at $833 \mathrm{~nm}$ (Fig. $2 \mathrm{~g}$ green).

Figure 3 compares a membrane-plane (side) and membrane-normal (periplasmic) view of the overall RC-LH1 'Core' complex structures from; Rba. sphaeroides, $\mathrm{pdb}$ 4V9G (Fig. 3a) (Qian et al. 2013), Rps. palustris (Fig. 3b) (Roszak et al. 2003), Tch. tepidum (Fig. 3c) (Yu et al. 2018), Blc. viridis (Fig. 3d) (Qian et al. 2018) and the RC-LH complex Rof. castenholzii (Fig. 3e) (Xin et al. 2018). Even at first glance, it is straightforward to classify the complexes into two groups, depending on whether they contain one RC with its LH1 ring, or two RCs joined together by a 'ribbon' of LH1, i.e., if they are 'monomers' or 'dimers'. Indeed, this classification was used for many years before the details of these newer structures became available. It is now apparent that 'monomeric' RC-LH1 'Core' complexes are much more prevalent in Nature than 'dimeric' complexes. Outside of the genus Rhodobacter, only one other dimeric RC-LH1 'Core' complex has been described, a $13 \AA$ electron microscopy projection structure from Rhodobaca bogoriensis (Semchonok et al. 2012). Rhodobaca is a haloalkaliphilic genus that is closely related to Rhodobacter and together they form the Rhodobacter-Rhodobaca (RR) group within the order Rhodobacterales (Kopejtka et al. 2017). It has been determined from extensive 16S rRNA phylogenetic analyses of phototrophic bacteria that only species within the RR group contain the pufX gene and, therefore, are able to make 'dimeric' complexes. The PufX protein is required for photosynthetic growth and plays a critical role in the dimerisation process as well as quinone/quinol exchange, Fig. 2a (Qian et al. 2017; Tunnicliffe et al. 2006). A more detailed inspection of the structures can also lead to a classification based on the presence or absence of a 'gap' in the LH1 ring. This feature is examined in more detail for the different species in Fig. 4. It should be borne in mind, however, that these pictures are drawn expressly to illustrate the way this exchange can occur. Pictures drawn using a (possibly more realistic) space-filling mode would show almost no space in the respective gaps/pores/channels. The importance of the quinone/quinol exchange mechanism had always been appreciated, even if the specific solution adopted by 
Fig. 3 In plane (side on view) and membrane-normal (top side, periplasmic view) views of RC-LH1 complexes. The colour scheme is the same as in Fig. 1 with the fixed Cytochrome $c$ given in salmon pink. a The dimeric complex from $R b a$. sphaeroides with gap-forming polypeptides PufX protein (red). b Rps. palustris with the gapforming Protein W (red). c The LH1 ring from the complex in Tch. tepidum has no discernible gap and the ring of $\mathrm{Ca}^{2+}$ ions (magenta) is visible between each successive $\alpha \beta$-pair. $\mathbf{d}$ The Blc. viridis complex contains an additional smaller $\gamma$-polypeptide (yellow) that intercalates between the $\beta$-helices on the outside of the ring. The absence of this polypeptide at one site facilitates quinone/quinol exchange. e The Rof. castenholzii complex with the previously unknown, channel-forming subunit X (red). The channel is also formed by a transmembrane helix that protrudes down from the fixed Cytochrome $c$ subunit. The enigmatic RC helix, TM7, mentioned in the text is represented in purple a
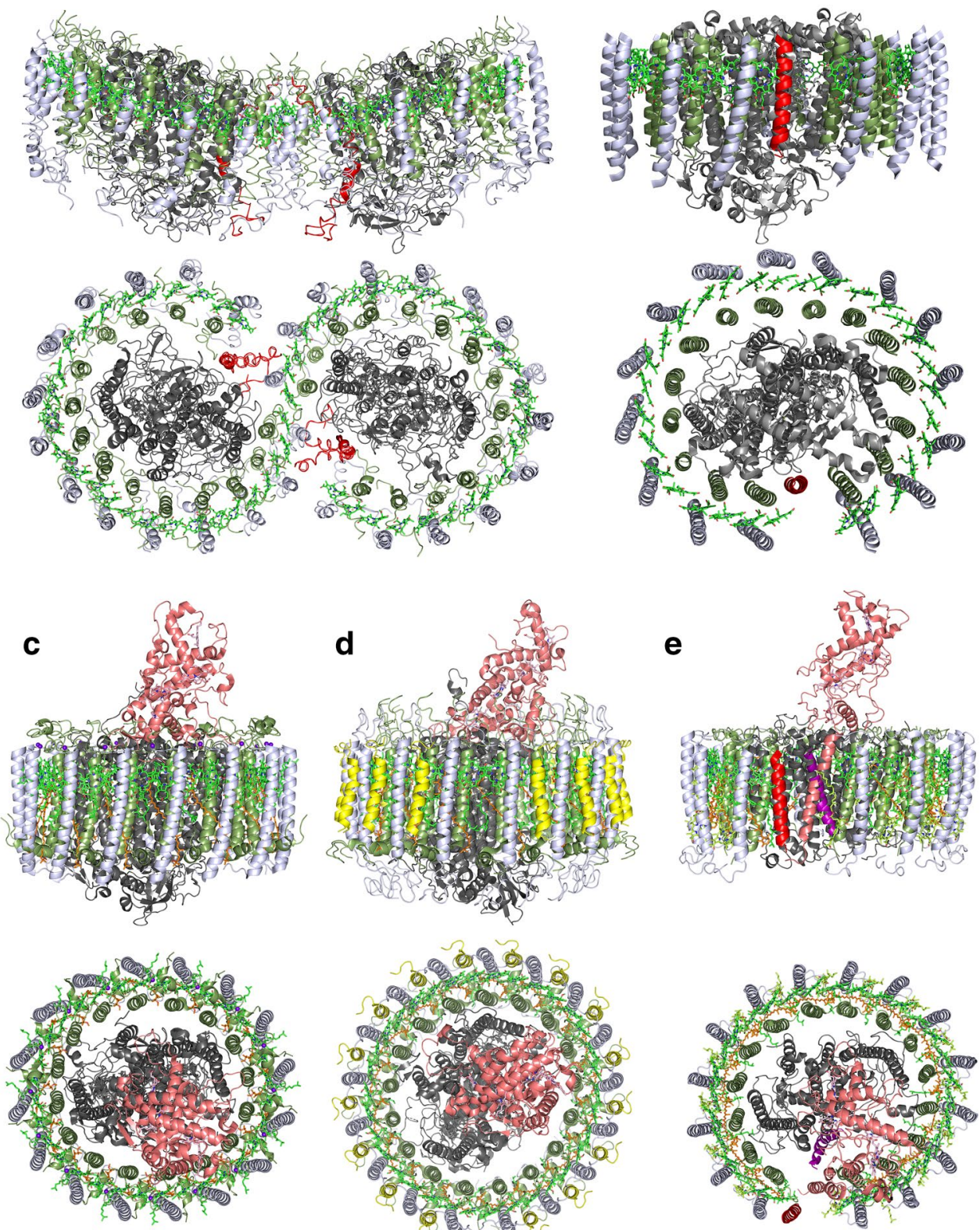

b

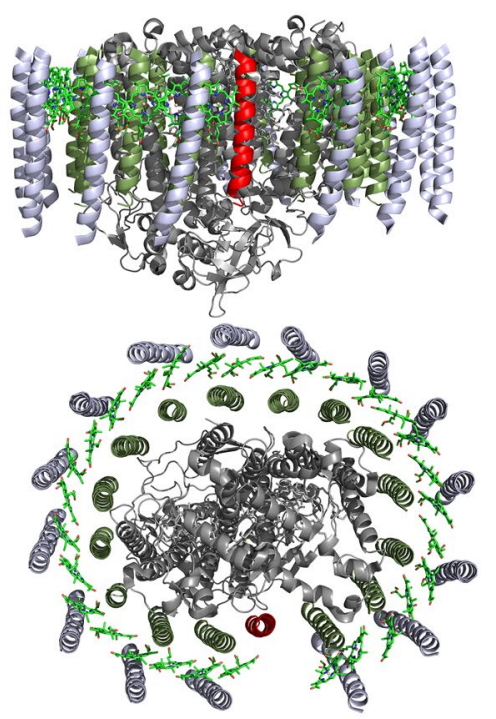

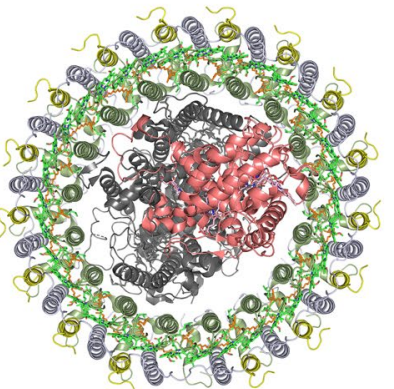

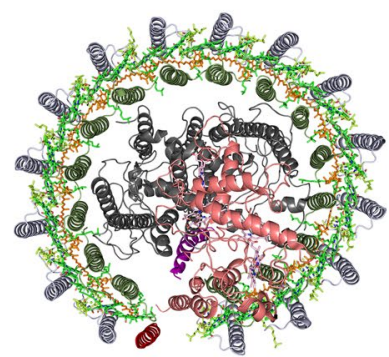

low-resolution models of the RC-LH1 'Core' complex (Miller 1982; Stark et al. 1984). The earlier study suggested that these complexes are hexagonal, whereas the second suggested that they are dodecameric. More recently, AFM has been used on these membranes and the results suggested the LH1 component around the RC is hexadecameric (Scheuring et al. 2003). It is, therefore, interesting that the true highresolution structure has shown that the LH1 component is a 17-mer, Fig. 3d. It is possible that these previous studies all made pre-conceived assumptions about the symmetry of the complex and then processed the data based on those assumptions. The different number of subunits obtained for images of the same complex clearly illustrates the inherent

The ICM from Blc. viridis contains large, regular hexagonal arrays of the RC-LH1 'Core' complexes. In the 1980s, these membranes were used in two EM studies that produced 

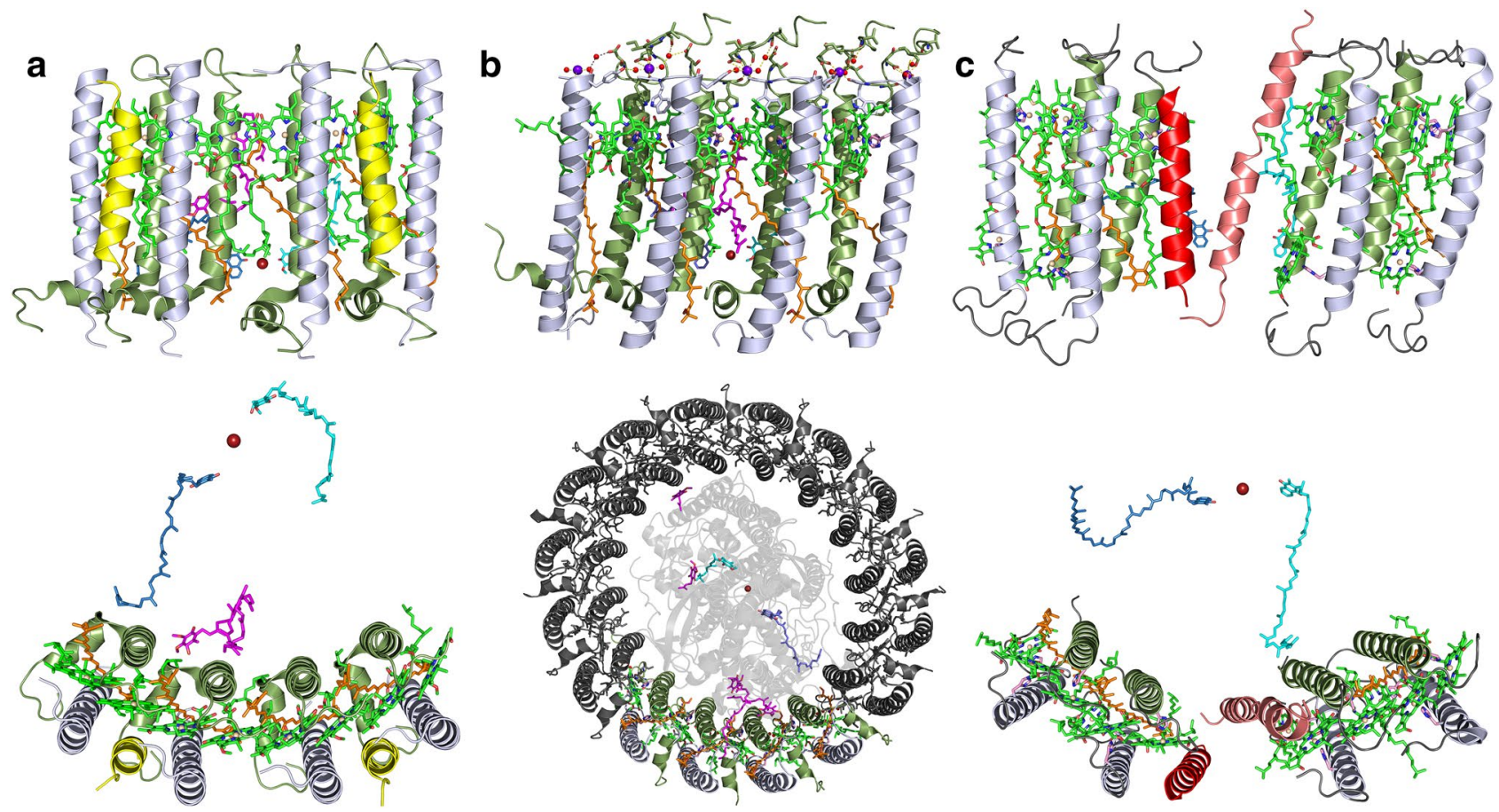

Fig. 4 Quinone/quinol exchange mechanisms used in the three highresolution structures mentioned in the text. The colour scheme is the same as in Fig. 1, with the non-haem iron in firebrick red, $Q_{A}$ quinone in blue, $\mathrm{Q}_{\mathrm{B}}$ in cyan and any additional quinones resolved in the structures are in magenta. The top row presents a side view of the four $\alpha \beta$-helices in the complex where quinone/quinol exchange is presumed to take place. The bottom row is the equivalent membranenormal view. Where required, a few of the terminal amino acids have been trimmed from the polypeptides termini in order to aid visibil-

danger if the imposed symmetry is wrong. As previously mentioned, the primary sequences of the LH1 apoproteins were published in the 1980s by the group of Herbert Zuber at ETH Zürich. They found that the RC-LH1 complex from Blc. viridis contains $\alpha$ - and $\beta$-polypeptides and an additional, smaller non-pigment binding apoprotein, called the $\gamma$-subunit, in a 1:1:1 ratio (Brunisholz et al. 1985). Even though this extra, smaller $\gamma$-polypeptide was described a long time ago, it was largely forgotten. It is rather rewarding to finally discover, after all this time, how the $\gamma$-subunit is organised in the overall structure of the RC-LH1, Figs. 1b and 3d (Qian et al. 2018). The LH1, slightly elliptical ring, is a 17-mer composed of $16 \alpha \beta \gamma$-trimers and one $\alpha \beta$-pair with no $\gamma$-subunit. The $\gamma$-subunits occupy a position on the outside of the ring between adjacent $\beta$-subunits. The space in the ring where this one $\gamma$-subunit is missing enables $a \sim 5$ $x \sim 7 \AA$ pore to be formed and quinone/quinol exchange to take place (Fig. 4a). In the structure, a folded quinone molecule has been visualised out with the $\mathrm{Q}_{\mathrm{B}}$ site that appears to be in the correct position to pass through the LH1 ring. It may appear from Fig. 4a that the tails of the Bchl and the end of the carotenoid may obstruct this exchange. However, ity. a Blc. viridis, the lower view is from the periplasmic side. b Tch. tepidum. The lower view shows the complete complex (minus the fixed cytochrome) from the cytoplasmic side with the same ring segment coloured that is presented above. The rest of the ring is given in grey and $80 \%$ transparency has been applied to the RC in order to help visualise $\mathrm{Q}_{\mathrm{A}}$ and $\mathrm{Q}_{\mathrm{B}}$. $\mathrm{c}$ Rof. castenholzii has a relatively big gap produced by helix $X$ (red) and the helix from the fixed Cytochrome (salmon pink). The lower view is from the periplasmic side

Qian et al. (2018) note that the densities for these parts of the molecules are less strong than in the equivalent molecules elsewhere in the ring and suggest that they have a degree of flexibility so that the pore is not blocked. In all sections of Fig. 4, the quinone occupying the $Q_{A}$ site is illustrated blue, the $\mathrm{Q}_{\mathrm{B}}$ site quinone in cyan and any additional quinones found are given in magenta.

Unlike the other RC-LH1 'Core' complexes that are described here, the complex from Blc. viridis contains Bchl $b$ (Eimhjellen et al. 1963), rather than $\mathrm{Bchl} a$, and its long wavelength, NIR absorption band, $\mathrm{Q}_{\mathrm{y}}$, is at $1004 \mathrm{~nm}$ (Fig. $2 \mathrm{~g}$ green). This absorption band is much further to the red than the corresponding band from the other Bchl $a$-containing complexes. A remarkable feature, as the NIR $\mathrm{Q}_{\mathrm{y}}$ absorption band of monomeric Bchl $b$ in organic solvent such as 7:2 (v/v) acetone:methanol is only $\sim 15 \mathrm{~nm}$ red shifted from that of Bchl $a$ in the same solvent (Scheer 1991). As mentioned previously, the overall molecular environment of any individual $\mathrm{Bchl}$ in its binding pocket sets that Bchl's site energy and this is as true for $\mathrm{Bchl} b$ as it is for $\mathrm{Bchl} a$. Parkes-Loach et al. (1990) have shown that reconstitution of the LH1 complex from Rsp. rubrum with Bchl $b$ resulted 
in an approximate $30 \mathrm{~nm}$ red shift relative to reconstitution with Bchl $a$. Recently, Swainsbury et al. (2019) showed that reconstituting the monomeric Bchl site in the $\mathrm{LH} 2$ complex from Rba. sphaeroides with $\mathrm{Bchl} b$ resulted in a $30 \mathrm{~nm}$ red shift relative to reconstitution with $\mathrm{Bchl} a$. It has been suggested, based on the structure of the Blc. viridis $\mathrm{RC}-\mathrm{LH} 1$ complex, that the additional red shift of the $\mathrm{Q} y$ absorption band is also due to stronger Bchl: Bchl interactions, as the $\mathrm{Bchl} b$ molecules are closer together than in the other types of RC-LH1 'Core' complex (Qian et al. 2018). These stronger interactions result in stronger exciton coupling and, therefore, a larger red shift. A full quantum mechanical calculation of the ring is required, using the position of each of the atoms in the structure, to test whether this hypothesis can be validated by theory (such as in Cupellini et al. (2016)). At $2.9 \AA$, however, the accuracy of any given atom position may not be sufficient, making the calculations unreliable or even not possible. This illustrates two interconnected points, first that small improvements in resolution can and do make real and tangible differences towards understanding the important details of a molecule. Secondly, a full understanding of the function does not come about just by having a highresolution structure per se, rather this requires further close co-operation between experimentalists and theoreticians and is particularly true for the complexes involved in the light reactions of anoxygenic photosynthesis, as there are no mechanical conformation changes or enzymatic intermediates that can be visualised. The fact that Blc. viridis contains $\mathrm{Bchl} b$ is not just some outlying curio in the world of photosynthetic bacteria. This species is very sensitive to the presence of oxygen (Lang and Oesterhelt 1989) and the resultant red shift of the LH1 NIR $\mathrm{Q}_{\mathrm{y}}$ absorption band results in a selective advantage for Blc. viridis in microaerophilic environments as this enables the cells to absorb solar energy that is unavailable to Bchl $a$-containing anoxygenic phototrophs (Pierson et al. 1990).

\section{The Thermochromatium tepidum 'Core' complex}

The structure of RC-LH1 'Core' from the thermophilic bacterium Tch. tepidum has been determined to $1.9 \AA$, the highest resolution so far for this type of complex, Fig. 3c (Niwa et al. 2014; Yu et al. 2018). The LH1 component is a 16-mer that forms an LH1 ellipse with no permanent gaps. It is suggested that the molecular motion of the LH1 in the membrane allows the complex to 'breathe' and so facilitates quinone/quinol exchange through a channel formed on the interfaces between each pair of adjacent apoprotein dimers (Fig. 4b top). This is supported by the finding in the structure of an isoprenoid tail from one quinone/quinol molecule present between the $\alpha$ - and $\beta$-subunits of LH1. The clear implication is that this represents a transient 'pore' through which the quinol molecule can pass, even though it is closer to $\mathrm{Q}_{\mathrm{A}}$ than $\mathrm{Q}_{\mathrm{B}}$. However, as the $\alpha \beta$-dimer subunits are all similar, the question arises if this is the only 'pore' present? One can speculate as to how many such 'pores' might exist and to what extent does the presence of the RC influence the 'breathing' of the ring (Fig. 4b bottom). These hypotheses need to be tested by detailed molecular dynamic simulations and is another example where theoreticians can make a significant contribution!

As can be seen from Fig. 2e, the Tch. tepidum LH1 has its major Bchl $a$ NIR $\mathrm{Q}_{\mathrm{y}}$ absorption band at $914 \mathrm{~nm}$. This red shift is rather less than that for Blc. viridis but significantly larger than for the other purple bacterial LH1 NIR $\mathrm{Q}_{\mathrm{y}} \mathrm{Bchl} a$ absorption bands, usually found between 875 and $890 \mathrm{~nm}$. This red shift correlates with the presence of tightly bound $\mathrm{Ca}^{2+}$ ion, one co-ordinated in the space between each $\alpha \beta$-dimer in the $\mathrm{C}$-terminal loop region, Figs. $1 \mathrm{c}$ and $4 \mathrm{~b}$ top (Kimura et al. 2008, 2009). The ends of the $\alpha \beta$-polypeptides in RC-LH1 (and LH2) complexes are, generally, quite flexible and may not be visible in the electron density maps. However, the presence of $\mathrm{Ca}^{2+}$, and the resulting network of bonds, restrains the ends of the polypeptides and has enabled them to be resolved by Yu et al. (2018). These authors successfully managed to determine that the binding site of these $\mathrm{Ca}^{2+}$ ions involves, in total, coordination with seven amino acid residues ( 5 on the $\alpha$-chain and two on the $\beta$-chain) and three water molecules, to form a beautiful bonded ring of $\mathrm{Ca}^{2+}$ around the periplasmic side of the complex. Interestingly, other divalent cations can substitute for $\mathrm{Ca}^{2+}$ in the Tch. tepidum RC-LH1 'Core' complex (Kimura et al. 2018). The structure of this complex has also been solved with either $\mathrm{Sr}^{2+}$ or $\mathrm{Ba}^{2+}$ substituting for $\mathrm{Ca}^{2+}$ (Yu et al. 2016). Substitution of the $\mathrm{Ca}^{2+}$ with either divalent metal ion results in a complex with the $\mathrm{Q}_{\mathrm{y}}$ band exhibiting a red shift to only $888 \mathrm{~nm}$. The network of bonds that co-ordinate the $\mathrm{Sr}^{2+}$ or $\mathrm{Ba}^{2+}$ ions originates only from the $\alpha$-polypeptide and results in a complex that has much reduced thermostability. Complete removal of these calcium ions also results in a blue shift of the $\mathrm{Bchl} a \mathrm{Q}_{\mathrm{y}}$ absorption band. Indeed, when the $\mathrm{Ca}^{2+}$-binding motif from Tch. tepidum was sequentially engineered into the LH1 antenna polypeptide sequences of Rba. sphaeroides, by progressively modifying the native $\mathrm{LH} 1$ polypeptides, $\mathrm{Ca}^{2+}$ binding was induced, and the extent of the red shift directly correlated with the proportion of Tch. tepidum sequence incorporated (Swainsbury et al. 2017). It has been suggested that loss of $\mathrm{Ca}^{2+}$ relaxes the structure and weakens the Bchl $a$ exciton coupling in the LH1 ring, resulting in a blue-shifted absorption band. It would be useful to have a high-resolution structure for the $\mathrm{Ca}^{2+}$-free complex to enable detailed quantum mechanical calculations to probe the possible molecular mechanisms that underlie this blue shift, and quantitatively test how the binding of $\mathrm{Ca}^{2+}$ influences the resulting structural rigidity of the complex. Thermostability of the complex induced by 
$\mathrm{Ca}^{2+}$ is important obviously for the organism, Tch. tepidum was first isolated from the Mammoth Hot Springs in Yellowstone National Park, but it is also a feature that may be exploited by synthetic biology as a template for engineering increased stability into other proteins.

\section{The Rhodopseudomonas palustris 'Core' complex}

The structure of the RC-LH1 'Core' complex from Rps. palustris was determined by X-ray crystallography to a resolution of $4.8 \AA$, Fig. 3b (Roszak et al. 2003). At this resolution, the structure should be viewed sensibly, and the limitations conferred at this resolution need to be appreciated. For example, the organisation of the Bchl $a$ molecules shown in Fig. 3b looks rather irregular compared with those in the Tch. tepidum (Fig. 3c) and results from a lack of detail in the electron density map at this resolution. Single molecule studies on the complex have shown clearly that the actual organisation of these Bchl $a$ molecules is indeed more regular (see Fig. 5 in Richter et al. (2007)). The Rps. palustris RC-LH1 'Core' complex has an elliptical 15-mer LH1 with a gap in the ring where Protein W (coloured red in Fig. 3b) is located. Protein W appears rather analogous to PufX in the Rba. sphaeroides complex, in that it provides the channel through which quinone/quinol exchange can take place. Elegant single molecule spectroscopy experiments have also provided strong evidence for the presence of the gap (Richter et al. 2007). Recently, however, a question has arisen following studies on a RC-LH1 'Core' complex from Rps. palustris, where Protein $\mathrm{W}$ was His-tagged, whether all the RC-LH1 'Core' complexes from this species actually contain W (Jackson et al. 2018). Further work is needed to clear up this anomaly and this complex is now a prime target for analysis by single particle cryo-EM where the structure should be able to be re-determined rather quickly.

\section{The Rhodobacter sphaeroides 'Core' complex}

The structure of the RC-LH1 'Core' complex from Rba. sphaeroides has been determined by X-ray crystallography to a resolution of $\sim 8 \AA$, with the resultant model built by using constraints provided by EM, NMR and mass spectrometry, Fig. 3a (Qian et al. 2013). It has two RC connected by an 'S'-shaped 'ribbon' of LH1 and so is called a 'dimeric' $\mathrm{RC}-\mathrm{LH} 1$ complex. The dimer is stabilised by the presence of two copies of a protein called PufX (coloured red in Fig. 3a), one for each LH1 ring. Deletion or mutation of PufX, and especially its C-terminus, results in an inability to form the dimer and a monomer is produced (Qian et al. 2017). PufX provides the channel through which the reduced quinones can exit the LH1 rings and connect with the cyclic electron transport pathway. Each LH1 ring consists of one RC, 14 $\alpha \beta$-subunits and one copy of PufX. The role of PufX was first suggested based on a series of papers from the groups of Oesterhelt and Hunter, and then confirmed by constructing deletion strains of Rba. sphaeroides (Barz et al. 1995a, b; Barz and Oesterhelt 1994; McGlynn et al. 1994). These groups showed that deletion of the pufX gene prevented photosynthetic growth by slowing down the rate of electron transfer from the RC quinol to Cytochrome $b / c_{l}$. This kinetic block could be removed by the deletion of the genes encoding LH1 (Lilburn and Beatty 1992; McGlynn et al. 1994), by point mutations in the LH1 polypeptides that promote a degree of structural rearrangement (Barz and Oesterhelt 1994) or by the removal of a hypothetical second carotenoid binding site (Olsen et al. 2017). The determination of the Rba. sphaeroides RC-LH1 'Core' complex structure beautifully provided a structural explanation for these molecular genetic deletion experiments.

\section{The Roseiflexus castenholzii 'Core' complex}

All the species of anoxygenic phototrophic bacteria mentioned previously belong to the class Alphaproteobacteria, apart from Tch. tepidum, which is a Gammaproteobacteria. The filamentous bacteria Rof. castenholzii is not a member of the Proteobacteria, rather belongs to the phylum Chloroflexi and was previously classed as a green non-sulphur bacterium. The structure of the RC-LH 'Core' complex from Rof. castenholzii has been determined by single particle cryo-EM to an overall average resolution of $4.1 \AA$, Fig. $3 \mathrm{e}$ (Xin et al. 2018). Note that these authors prefer to use the term $\mathrm{RC}-\mathrm{LH}$ rather than $\mathrm{RC}-\mathrm{LH} 1$ to describe this complex. The structure bears a superficial resemblance to the other 'monomeric' complexes presented in Fig. 3 but, perhaps not surprisingly given the evolutionary diversity, has some significant unique differences. The $\mathrm{RC}$ is rather different to the $\mathrm{RC}$ in proteobacteria; the LM-subunit contains separate Land $\mathrm{M}$ - polypeptides but they are encoded by a single fused pufLM gene (Yamada et al. 2005). Six transmembrane helices make up the L subunit and five transmembrane helices comprise the M-subunit. The presumed sixth transmembrane helix of the M-subunit was found to have non-continuous density with the other helices and so was modelled as a separate helix in the structure, termed TM7 (identifier Y in the pdb and coloured purple in Fig. 3e). It is presently unclear whether TM7 really is a separate protein and, if so, whether it is the product of (i) an, as yet, unidentified gene or (ii) results from even more post-translational processing of the nascent PufLM polypeptide than was previously envisioned. The L-M-TM7-subunit contains 3 Bchl $a$ and 3 Bacteriopheophytin (Bphe) $a$ instead of 4 and 2, respectively, (Collins et al. 2010) and the kinetic properties of the RC are rather similar to other previously studied RC purple bacteria (Collins et al. 2011). There is no indication in these previous studies on the Rof. castenholzii RC that any triplet states 
formed in the Bchl 'special pair' $\mathrm{P}$ are not being quenched, i.e. the carotenoid in the $\mathrm{RC}$ is functioning normally. However, in the structure no RC carotenoid was resolved and the reasons for this are not at all clear. The molecule could well be more flexible than the equivalent in purple bacterial RCs but then one could still expect some of the molecule to be resolved, e.g. the area around the cis-bond, but this appears to be not the case. There is one further, particularly intriguing feature of the RC from this species and that is that it contains no H-subunit. This is evident in Fig. 3e and is particularly interesting as it has been previously assumed that the $\mathrm{H}$-subunit plays a central role in the formation of RC-LH1 in the membrane. The H-subunit is inserted first, and this acts as an anchor about which the rest of the RC, and then LH1, is built. As the Rof. castenholzii LH-RC has no RC-H, either this assumption is incorrect or the assembly pathway is rather different in Chloroflexi compared with that in all other known anoxygenic phototrophs.

The LH ring contains $15 \alpha \beta$-subunits but the position where a $16^{\text {th }}$ subunit (e.g. by analogy with the Tch. tepidum complex) would be is replaced by a channel formed by a quite novel method. A previously unknown polypeptide, called X (coloured red in Fig. 4c), forms a transmembrane helix and sits on the outer side of the LH1 ring. This is complemented by an extension from the fixed Cytochrome $c$ that protrudes downward to form a transmembrane helix on the inner side of the ring (coloured salmon pink in Fig. 4c). These two proteins create the channel through which quinone/quinol exchange is able to take place. The presence in the channel area of transmembrane Helix X and the transmembrane helix from the fixed Cytochrome occupy more space in the structure than just the missing 16 th $\alpha \beta$-subunit. This is reflected in the loss of one carotenoid molecule from the ring so that only 14 are present.

The other unique feature of this RC-LH 'Core' complex is that the $\mathrm{LH} \alpha \beta$-dimer subunit binds three $\mathrm{Bchl}$ molecules rather than two, which is typical for the other complexes in Fig. 3, so that there are $45 \mathrm{Bchl} a$ molecules per RC (Collins et al. 2010). The $\alpha \beta$-dimer (Fig. 1d) contains the two Bchl $a$ molecules that give rise to the 'normal' LH1 NIR $\mathrm{Q}_{\mathrm{y}}$ absorption band at $879 \mathrm{~nm}$ and an additional, more weakly coupled monomeric Bchl $a$ molecule that produces the second NIR $\mathrm{Q}_{\mathrm{y}}$ absorption band at $800 \mathrm{~nm}$. Some anoxygenic phototrophic Proteobacteria are able to produce a LH2 complex in the ICM in addition to the RC-LH1, yet other species perform light-harvesting and grow under phototrophic conditions perfectly well without LH2. It is interesting to note the striking similarities between the Rbl. acidophilus LH2 $\alpha \beta$-dimer, Fig. 1a, and the Rof. castenholzii LH1 $\alpha \beta$-dimer, Fig. 1d, with the only major difference being the different ligation method and orientation of the monomeric Bchl $a$. Usually in photosynthetic complexes, the $\mathrm{Mg}$ atom of chlorophyll/Bchl molecules is liganded by histidine residues. In the LH2 complex from Rbl. acidophilus, the $\mathrm{Mg}$ atom of the monomeric Bchl $a$ is ligated via a carboxyl group extension of the $\mathrm{N}$-terminal methionine residue of the $\alpha$-apoprotein (Fig. 1a) (Papiz et al. 2003). The central Mg atom in the monomeric Bchl $a$ in the LH2 complex from Phs. molischianum is ligated to $\alpha$-Aspartate- 6 , present in an amphiphilic $\mathrm{N}$-terminal $3_{10}$ helix located at the membrane-water interface (Koepke et al. 1996). In both these LH2 complexes, the fact that this Mg-ligating bond (there are additional, less important stabilising contacts to these monomeric $\mathrm{Bchl} a$ molecules but these are omitted for brevity) originates from the end of the $\mathrm{N}$-terminus results in the bacteriochlorin ring of the Bchl $a$ being held in an orientation that is approximately in the plane of the membrane. In fact, the bacteriochlorin rings of the monomeric Bchl population from these two LH2s are tilted with respect to each other by about $20^{\circ}$ and rotated by $90^{\circ}$. This does not happen in the Rof. castenholzii $\mathrm{RC}-\mathrm{LH}$ complex. The $\mathrm{Mg}$ atom in the monomeric $\mathrm{Bchl} a$ is 'conventionally' liganded to the Histidine-26 residue in the $\beta$-helix and so this ensures that the bacteriochlorin ring adopts an orientation that is approximately normal to the membrane plane. The $\mathrm{N}$-terminus of either polypeptide has no role in the binding of the monomeric Bchl in this complex (Fig. 1d).

This evolutionary distant member of the Chloroflexi produces a RC-LH complex with a LH ring that is a subtle hybrid of LH1 and LH2. However, there are still many open questions with regard to this complex; what is the genetic origin and sequence of helix X? How is the pufLM gene product processed so that it gives rise to three and not two proteins? Or is TM7 a completely independent protein that is coded for by its own gene? What is the correct status of the 'missing' carotenoid in the RC? These are just some of the uncertainties that need to be answered by further research on this interesting complex. Indeed, as Roseiflexus is a genus of bacteria in the family Roseiflexaceae, with Rof. castenholzii as the only known species. It is fascinating to consider what other species may be present in Nature, as yet undiscovered, and how they might have evolved.

\section{The Gemmatimonas phototrophica 'Core' structure}

Gemmatimonas (Gem.) phototrophica is the only phototrophic representative as yet described of the bacterial phylum Gemmatimonadetes (Zeng et al. 2014). This species is an aerobic anoxygenic phototroph (AAP) meaning that it obtains its metabolic energy through respiration and only uses photosynthesis to supplement growth. These authors suggested that Gem. phototrophica gained this ability by a lateral gene transfer event of the 'purple' bacterial photosynthetic gene cluster. A high-resolution structure is not yet available; however, it is now known that this species has a remarkable RC-LH1 'Core' complex that is much larger than the other 
single-RC complexes mentioned above. The RC-LH1 'Core' from Gem. phototrophica contains approximately $62.4 \pm 4.7$ Bchl $a$ molecules per RC and has a circular particle size diameter of approximately $190 \AA$ and a molecular mass of around $800 \pm 100 \mathrm{kDa}$ (Dachev et al. 2017. By contrast, the LH1 ring in Tch. tepidum contains $32 \mathrm{Bchl} a(2$ per $\alpha \beta$-dimer) and has an elliptical size of $105 \times 96 \AA$ and a mass of some $426 \mathrm{kDa}$. The additional Bchl $a$ molecules in the Gem. phototrophica RC-LH1 'Core' are located in a second, outer concentric ring around a more 'typical' inner LH1 ring. The absorption spectrum of this double ring structure has Bchl $a$ NIR $\mathrm{Q}_{\mathrm{y}}$ absorption bands at 816 and $868 \mathrm{~nm}$. It has been proposed that the $816 \mathrm{~nm}$ band arises from the outer ring and the $868 \mathrm{~nm}$ band comes from the inner ring. This then sets up an intramolecular, downhill energy gradient in which light energy can be funnelled from the outer to the inner ring and on to the RC. In a sense, this complex makes a nice complement to the Rof. castenholzii RC-LH mentioned in the previous section. The Rof. castenholzii complex, functionally, has elements of an LH2 complex by incorporating the extra, weakly coupled Bchl $a$ in the LH1 ring to produce an additional, blue-shifted absorption band. Gem. phototrophica goes one step further by producing an extra ring in its RC-LH1 'Core', rather than making a separate LH2 complex. At present there is only a low-resolution, single particle image of this complex (Dachev et al. 2017). A higher resolution cryo-EM structure is eagerly awaited when, hopefully, a full structural description of the two populations of $\mathrm{Bchl} a$ molecules will allow their spectroscopic properties to be studied and understood.

\section{Final remarks}

There are now a number of structures of RC-LH1 'Core' complexes from different species of anoxygenic phototrophic bacteria. Remarkably, despite the evolutionary diversity involved, the differences highlighted above are elegant variations on a basic theme. In each case, the Bchl $a$ molecules present in LH1 form a strongly exciton-coupled 'ring(s)' around the RC in a way that the distance to the Bchl $a$ 'special pair' in the RC is short enough to allow fast and efficient energy transfer but long enough to completely prohibit electron transfer (Moser et al. 2003). Similarly, a single 'gap' in the LH1 ring would suffice to enable quinone/quinol exchange to take place. Yet, already, within this extremely small total number of structures available, wonderful and elegant solutions have evolved to connect the $\mathrm{Q}_{\mathrm{B}}$ site with the bulk quinone pool in the membrane. Understandably, perhaps, previous work has concentrated on species that are/were classed as 'purple' bacteria. However, the novel structure of the RC-LH from Rof. castenholzii (Xin et al. 2018) and, particularly the concentric double ringed RC-LH1 complex from Gem. phototrophica (Dachev et al. 2017), suggests that further interesting complexes and adaptations remain to be discovered. Further work by biochemists, spectroscopists, theoreticians and physiologists is now needed to fully understand the benefits that these structural variations provide the different bacterial species in their specific ecological niches.

Acknowledgements The authors would like to thank Prof. Z-Y. WangOtomo for providing an absorption spectrum of the RC-LH1 'Core' complex from Thermochromatium tepidum. ATG and RJC gratefully acknowledge funding from the Photosynthetic Antenna Research Center (PARC), an Energy Frontier Research Center funded by the Department of Energy, Office of Science, Office of Basic Energy Sciences under Award Number DE-SC0001035. TCN-P and RJC thank the Biotechnology and Biological Sciences Research Council for the financial support.

Author contributions ATG wrote the manuscript and prepared the figures. TCN-P wrote the manuscript and prepared the table. RJC wrote the manuscript and mentored its preparation.

Funding ATG and RJC received funding from the Photosynthetic Antenna Research Center (PARC), an Energy Frontier Research Center funded by the Department of Energy, Office of Science, Office of Basic Energy Sciences under Award Number DE-SC0001035. TCN-P and RJC thank the Biotechnology and Biological Sciences Research Council for the financial support.

Code availability Figures were prepared using legally licenced versions of Pymol or Origin 9.

\section{Compliance with ethical standards}

Conflicts of interest There are no conflicts of interest.

Open Access This article is licensed under a Creative Commons Attribution 4.0 International License, which permits use, sharing, adaptation, distribution and reproduction in any medium or format, as long as you give appropriate credit to the original author(s) and the source, provide a link to the Creative Commons licence, and indicate if changes were made. The images or other third party material in this article are included in the article's Creative Commons licence, unless indicated otherwise in a credit line to the material. If material is not included in the article's Creative Commons licence and your intended use is not permitted by statutory regulation or exceeds the permitted use, you will need to obtain permission directly from the copyright holder. To view a copy of this licence, visit http://creativecommons.org/licenses/by/4.0/.

\section{References}

Aagaard J, Sistrom WR (1972) Control of synthesis of reaction center bacteriochlorophyll in photosynthetic bacteria. Photochem Photobiol 15:209. https://doi.org/10.1111/j.1751-1097.1972.tb06240.x

Barz WP, Francia F, Venturoli G, Melandri BA, Vermeglio A, Oesterhelt D (1995a) Role of PufX protein in photosynthetic growth of Rhodobacter sphaeroides 1 PufX is required for efficient light-driven electron transfer and photophosphorylation under anaerobic conditions. Biochemistry 34:15235-15247. https://doi. org/10.1021/bi00046a032

Barz WP, Oesterhelt D (1994) Photosynthetic deficiency of a pufX deletion mutant of Rhodobacter sphaeroides is suppressed by 
point mutations in the light-harvesting complex genes pufB or pufA. Biochemistry 33:9741-9752. https://doi.org/10.1021/bi001 $98 \mathrm{a} 045$

Barz WP, Vermeglio A, Francia F, Venturoli G, Melandri BA, Oesterhelt D (1995b) Role of the PufX protein in photosynthetic growth of Rhodobacter sphaeroides. 2. PufX is required for efficient ubiquinone/ubiquinol exchange between the reaction center $\mathrm{QB}$ site and the cytochrome bc1 complex. Biochemistry 34:1524815258. https://doi.org/10.1021/bi00046a033

Brunisholz RA, Jay F, Suter F, Zuber H (1985) The light-harvesting polypeptides of Rhodopseudomonas viridis. The complete aminoacid sequences of B1015-alpha, B1015-beta and B1015-gamma. Biol Chem Hoppe-Seyler 366:87-98. https://doi.org/10.1515/ bchm3.1985.366.1.87

Clayton RK (1966) Spectroscopic Analysis of Bacteriochlorophylls in vitro and in vivo. Photochem Photobiol 5:669-677. https://doi. org/10.1111/j.1751-1097.1966.tb05813.x

Cogdell RJ, Gardiner AT, Roszak AW, Law CJ, Southall J, Isaacs NW (2004) Rings, ellipses and horseshoes: how purple bacteria harvest solar energy. Photosynth Res 81:207-214. https://doi. org/10.1023/B:PRES.0000036883.56959.a9

Cogdell RJ, Howard TD, Isaacs NW, McLuskey K, Gardiner AT (2002) Structural factors which control the position of the Qy absorption band of bacteriochlorophyll a in purple bacterial antenna complexes. Photosynth Res 74:135-141. https://doi. org/10.1023/A:1020995224156

Cogdell RJ, Roszak AW (2014) The purple heart of photosynthesis. Nature 508:196-197. https://doi.org/10.1038/nature13219

Collins AM, Kirmaier C, Holten D, Blankenship RE (2011) Kinetics and energetics of electron transfer in reaction centers of the photosynthetic bacterium Roseiflexus castenholzii. Biochim Biophys Acta 1807:262-269. https://doi.org/10.1016/j.bbabio.2010.11.011

Collins AM, Qian P, Tang Q, Bocian DF, Hunter CN, Blankenship RE (2010) Light-harvesting antenna system from the phototrophic bacterium Roseiflexus castenholzii. Biochemistry 49:7524-7531. https://doi.org/10.1021/bi101036t

Cupellini L et al (2016) An ab initio description of the excitonic properties of LH2 and their temperature dependence. J Phys Chem 120:11348-11359. https://doi.org/10.1021/acs.jpcb.6b06585

Dachev $\mathrm{M}$ et al (2017) Unique double concentric ring organization of light harvesting complexes in Gemmatimonas phototrophica. PLoS Biol 15:e2003943. https://doi.org/10.1371/journ al.pbio.2003943

Eimhjellen KE, Jensen A, Aasmundrud O (1963) A new bacterial chlorophyll. Biochem Biophys Res Commun 10:232. https://doi. org/10.1016/0006-291x(63)90422-4

Gabrielsen M, Gardiner AT, Cogdell RJ (2009) Peripheral complexes of purple bacteria. In: Hunter CN, Daldal F, Thurnauer MC, Beatty JT (eds) The purple phototrophic bacteria. Advances in photosynthesis and respiration. Springer, Dordrecht, pp 135-15328

Gardiner AT, Cogdell RJ, Takaichi S (1993) The effect of growth conditions on the light-harvesting apparatus in Rhodopseudomonas acidophila. Photosynth Res 38:159-167. https://doi.org/10.1007/ BF00146415

Hu X, Damjanović A, Ritz T, Schulten K (1998) Architecture and mechanism of the light-harvesting apparatus of purple bacteria. Proc Natl Acad Sci USA 95:5935-5941. https://doi.org/10.1073/ pnas.95.11.5935

Jackson PJ et al (2018) Identification of protein W, the elusive sixth subunit of the Rhodopseudomonas palustris reaction center-light harvesting 1 core complex. Biochim Biophys Acta Bioenerg 1859:119-128. https://doi.org/10.1016/j.bbabio.2017.11.001

Jamieson SJ, Wang P, Qian P, Kirkland JY, Conroy MJ, Hunter CN, Bullough PA (2002) Projection structure of the photosynthetic reaction centre-antenna complex of Rhodospirillum rubrum at
8.5 Å resolution. Embo J 21:3927-3935. https://doi.org/10.1093/ emboj/cdf410

Karrasch S, Bullough PA, Ghosh R (1995) The 8.5-angstrom projection map of the light-harvesting complex-I from rhodospirillumrubrum reveals a ring composed of 16 subunits. Embo J 14:631638. https://doi.org/10.1002/j.1460-2075.1995.tb07041.x

Kereïche $S$ et al (2008) The peripheral light-harvesting complexes from purple sulfur bacteria have different 'ring' sizes. FEBS Lett 582:3650-3656. https://doi.org/10.1016/j.febslet.2008.09.050

Kimura $\mathrm{Y}$ et al (2018) Biochemical and spectroscopic characterizations of a hybrid light harvesting reaction center core complex. Biochemistry. https://doi.org/10.1021/acs.biochem.8b00644

Kimura Y, Hirano Y, Yu L-J, Suzuki H, Kobayashi M, Wang Z-Y (2008) Calcium ions are involved in the unusual red-shift of the light-harvesting. 1. Qy transition of the core complex in thermophilic purple sulfur bacterium Thermochromatium tepidum. J Biol Chem 283:13867-13873. https://doi.org/10.1074/jbc.M8002 56200

Kimura Y, Yu LJ, Hirano Y, Suzuki H, Wang ZY (2009) Calcium ions are required for the enhanced thermal stability of the light-harvesting-reaction center core complex from thermophilic purple sulfur bacterium Thermochromatium tepidum. J Biol Chem 284:93-99. https://doi.org/10.1074/jbc.M806840200

Koepke J, Hu X, Muenke C, Schulten K, Michel H (1996) The crystal structure of the light-harvesting complex II (B800-850) from Rhodospirillum molischianum. Structure 4:581-597. https://doi. org/10.1016/S0969-2126(96)00063-9

Kopejtka K, Tomasch J, Zeng Y, Tichý M, Sorokin DY, Koblížek M (2017) Genomic analysis of the evolution of phototrophy among haloalkaliphilic rhodobacterales. Genome Biol Evol 9:1950-1962. https://doi.org/10.1093/gbe/evx141

Lang FS, Oesterhelt D (1989) Microaerophilic growth and induction of the photosynthetic reaction center in Rhodopseudomonas viridis. J Bacteriol 171:2827-2834. https://doi.org/10.1128/ jb.171.5.2827-2834.1989

Liang B, Tamm LK (2016) NMR as a tool to investigate the structure, dynamics and function of membrane proteins. Nat Struct Mol Biol 23:468-474. https://doi.org/10.1038/nsmb.3226

Lilburn TG, Beatty JT (1992) Suppressor mutants of the photosynthetically incompetent pufX deletion mutant Rhodobacter capsulatus $\Delta$ RC6(pTL2). FEMS Microbiol Lett 100:155-159. https://doi. org/10.1111/j.1574-6968.1992.tb14034.x

Ma J, You X, Sun S, Wang X, Qin S, Sui S-F (2020) Structural basis of energy transfer in Porphyridium purpureum phycobilisome. Nature. https://doi.org/10.1038/s41586-020-2020-7

McDermott A (2009) Structure and dynamics of membrane proteins by magic angle spinning solid-state NMR. Ann Rev Biophys 38:385403. https://doi.org/10.1146/annurev.biophys.050708.133719

McDermott G, Prince SM, Freer AA, Hawthornthwaite-Lawless AM, Papiz MZ, Cogdell RJ, Isaacs NW (1995) Crystal structure of an integral membrane light-harvesting complex from photosynthetic bacteria. Nature 374:517-521. https://doi.org/10.1038/374517a0

McGlynn P, Hunter CN, Jones MR (1994) The Rhodobacter sphaeroides PufX protein is not required for photosynthetic competence in the absence of a light harvesting system. FEBS Lett 349:349-353. https://doi.org/10.1016/0014-5793(94)00701-2

Miller KR (1982) Three-dimensional structure of a photosynthetic membrane. Nature 300:53-55. https://doi.org/10.1038/300053a0

Moser CC, Page CC, Cogdell RJ, Barber J, Wraight CA, Dutton PL (2003) Length, time, and energy scales of photosystems. Adv Protein Chem 63:71-109. https://doi.org/10.1016/s0065 -3233(03)63004-4

Niwa S, Yu L-J, Takeda K, Hirano Y, Kawakami T, Wang-Otomo Z-Y, Miki K (2014) Structure of the LH1-RC complex from thermochromatium tepidum at $3.0 \AA$ A. Nature 508:228-232. https://doi. org/10.1038/nature 13197 
Nogales E (2018) Profile of Joachim Frank, Richard Henderson, and Jacques Dubochet, 2017 nobel laureates in chemistry. Proc Natl Acad Sci USA 115:441-444. https://doi.org/10.1073/pnas.17188 98114

Nottoli M, Jurinovich S, Cupellini L, Gardiner AT, Cogdell R, Mennucci B (2018) The role of charge-transfer states in the spectral tuning of antenna complexes of purple bacteria. Photosynth Res 137:215-226. https://doi.org/10.1007/s11120-018-0492-1

Olsen JD, Martin EC, Hunter CN (2017) The PufX quinone channel enables the light-harvesting 1 antenna to bind more carotenoids for light collection and photoprotection. FEBS Lett 591:573-580. https://doi.org/10.1002/1873-3468.12575

Papiz MZ, Prince SM, Howard T, Cogdell RJ, Isaacs NW (2003) The structure and thermal motion of the B800-850 LH2 complex from Rhodopseudomonas.acidophila at $2.0 \AA$ resolution and $100 \mathrm{~K}$ : new structural features and functionally relevant motions. J Mol Biol 326:1523-1538. https://doi.org/10.1016/ s0022-2836(03)00024-x

Parkes-Loach PS, Michalski TJ, Bass WJ, Smith U, Loach PA (1990) Probing the bacteriochlorophyll binding site by reconstitution of the light-harvesting complex of Rhodospirillum rubrum with bacteriochlorophyll a analogs. Biochemistry 29:2951-2960. https:// doi.org/10.1021/bi00464a010

Pierson BK, Sands VM, Frederick JL (1990) Spectral irradiance and distribution of pigments in a highly layered marine microbial mat. Appl Environ Microbiol 56:2327-2340

Pugh RJ, McGlynn P, Jones MR, Hunter CN (1998) The LH1-RC core complex of Rhodobacter sphaeroides: interaction between components, time-dependent assembly, and topology of the PufX protein. Biochim Biophys Acta 1366:301-316. https://doi. org/10.1016/s0005-2728(98)00131-5

Qian P, Martin EC, Ng IW, Hunter CN (2017) The C-terminus of PufX plays a key role in dimerisation and assembly of the reaction center light-harvesting 1 complex from Rhodobacter sphaeroides. Biochim Biophys Acta Bioenergy 1858:795-803. https://doi. org/10.1016/j.bbabio.2017.06.001

Qian P et al (2013) Three-dimensional structure of the Rhodobacter sphaeroides RC-LH1-PufX complex: dimerization and quinone channels promoted by PufX. Biochemistry 52:7575-7585. https ://doi.org/10.1021/bi4011946

Qian P, Siebert CA, Wang P, Canniffe DP, Hunter CN (2018) Cryo-EM structure of the Blastochloris viridis LH1-RC complex at $2.9 \AA$. Nature 556:203-208. https://doi.org/10.1038/s41586-018-0014-5

Richter MF, Baier J, Southall J, Cogdell RJ, Oellerich S, Köhler J (2007) Refinement of the X-ray structure of the RC-LH1 core complex from Rhodopseudomonas palustris by single-molecule spectroscopy. Proc Natl Acad Sci USA 104:20280. https://doi. org/10.1073/pnas.0704599105

Robert B, Cogdell RJ, Van Grondelle R (2003) The light- harvesting system of purple bacteria. In: Green BR, Parson WW (eds) Light-harvesting antennas in photosynthesis. Kluwer Academic Publishers, Dordrecht, pp 169-194

Roszak AW, Howard TD, Southall J, Gardiner AT, Law CJ, Isaacs NW, Cogdell RJ (2003) Crystal structure of the RC-LH1 core complex from Rhodopseudomonas palustris. Science 302:1969-1972. https ://doi.org/10.1126/science.1088892

Scheer H (1991) Structure and occurrence of chlorophylls. In: Scheer $\mathrm{H}$ (ed) Chlorophylls. CRC Press, Boca Raton, pp 3-30

Scheuring S, Seguin J, Marco S, Lévy D, Robert B, Rigaud J-L (2003) Nanodissection and high-resolution imaging of the Rhodopseudomonas viridis photosynthetic core complex in native membranes by AFM. Proc Natl Acad Sci USA 100:1690-1693. https ://doi.org/10.1073/pnas.0437992100

Semchonok DA, Chauvin J-P, Frese RN, Jungas C, Boekema EJ (2012) Structure of the dimeric RC-LH1-PufX complex from Rhodobaca bogoriensis investigated by electron microscopy. Philos Trans R Soc 367:3412-3419. https://doi.org/10.1098/rstb.2012.0063

Southall J et al (2018) Characterisation of a pucBA deletion mutant from Rhodopseudomonas palustris lacking all but the pucBAd genes. Photosynth Res 135:9-21. https://doi.org/10.1007/s1112 0-017-0386-7

Stark W, Kühlbrandt W, Wildhaber I, Wehrli E, Mühlethaler K (1984) The structure of the photoreceptor unit of Rhodopseudomonas viridis. Embo J 3:777-783

Sundström V, van Grondelle R (1995) Kinetics of excitation transfer and trapping in purple bacteria. In: Blankenship RE, Madigan MT, Bauer CE (eds) Anoxygenic photosynthetic bacteria. Advances in photosynthesis and respiration. Springer, Dordrecht, pp 349-3722

Swainsbury DJK et al (2019) Engineering of B800 bacteriochlorophyll binding site specificity in the Rhodobacter sphaeroides LH2 antenna. Biochim Biophys Acta Bioenergy 1860:209-223. https ://doi.org/10.1016/j.bbabio.2018.11.008

Swainsbury DJK, Martin EC, Vasilev C, Parkes-Loach PS, Loach PA, Hunter CN (2017) Engineering of a calcium-ion binding site into the RC-LH1-PufX complex of Rhodobacter sphaeroides to enable ion-dependent spectral red-shifting. Biochim Biophys Acta Bioenergy 1858:927-938. https://doi.org/10.1016/j.bbabio.2017.08.009

Tunnicliffe RB, Ratcliffe EC, Hunter CN, Williamson MP (2006) The solution structure of the PufX polypeptide from Rhodobacter sphaeroides. FEBS Lett 580:6967-6971. https://doi.org/10.1016/j. febslet.2006.11.065

Xin Y, Pan J, Collins AM, Lin S, Blankenship RE (2012) Excitation energy transfer and trapping dynamics in the core complex of the filamentous photosynthetic bacterium Roseiflexus castenholzii. Photosynth Res 111:149-156. https://doi.org/10.1007/s1112 0-011-9669-6

Xin Y et al (2018) Cryo-EM structure of the RC-LH core complex from an early branching photosynthetic prokaryote. Nat Commun 9:1568. https://doi.org/10.1038/s41467-018-03881-x

Yamada M, Zhang H, Hanada S, Nagashima KVP, Shimada K, Matsuura K (2005) Structural and spectroscopic properties of a reaction center complex from the chlorosome-lacking filamentous anoxygenic phototrophic bacterium Roseiflexus castenholzii. J Bacteriol 187:1702. https://doi.org/10.1128/JB.187.5.1702-1709.2005

Yu L-J, Kawakami T, Kimura Y, Wang-Otomo Z-Y (2016) Structural basis for the unusual qy red-shift and enhanced thermostability of the LH1 complex from Thermochromatium tepidum. Biochemistry 55:6495-6504. https://doi.org/10.1021/acs.biochem.6b00742

Yu L-J, Suga M, Wang-Otomo Z-Y, Shen J-R (2018) Novel features of LH1-RC from Thermochromatium tepidum revealed from its atomic resolution structure. FEBS J 285:4359-4366. https://doi. org/10.1111/febs.14679

Zeng Y, Feng F, Medová H, Dean J, Koblížek M (2014) Functional type 2 photosynthetic reaction centers found in the rare bacterial phylum Gemmatimonadetes. Proc Natl Acad Sci USA 111:7795. https://doi.org/10.1073/pnas.1400295111

Zhang J, Ma J, Liu D, Qin S, Sun S, Zhao J, Sui S-F (2017) Structure of phycobilisome from the red alga Griffithsia pacifica. Nature. https://doi.org/10.1038/nature24278

Zuber H (1987) The structure of the light-harvesting pigment-protein complexes. In: Barber J (ed) The light reactions. Topics in photosynthesis, vol 8. Elsevier, Amsterdam, pp 197-259

Zuber H, Cogdell RJ (1995) Structure and organisation of purple bacterial antenna complexes. In: Blankenship RE, Madigan M, Bauer $\mathrm{C}$ (eds) Anoxygenic photosynthetic bacteria. Kluwer Academic Publishers, Dordrecht, pp 315-348

Publisher's Note Springer Nature remains neutral with regard to jurisdictional claims in published maps and institutional affiliations. 